\title{
Valproic Acid Enhance Reprogramming of Bactrian Camel Cells through Promoting the Expression of Endogenous Gene c-Myc and the Process of Angiogenesis
}

\author{
Zongshuai Li, Wenbo Ge, Yina Li, Yong Zhang, Xingxu Zhao, Junjie $\mathrm{Hu}$ \\ Department of Veterinary Obstetrics, College of Veterinary Medicine, Gansu Agricultural University, Lanzhou, China
}

\begin{abstract}
Background and Objectives: Induced pluripotent stem cells (iPSCs) are usually generated by reprogramming differentiated cells through the introduction of specific transcription factors, but this is a difficult and inefficient process. Valproic acid (VPA) is a histone deacetylase inhibitor that significantly improves the efficiency of iPSC generation. But its role and mechanism are still unclear.

Methods and Results: We transduced Bactrian camel fetal fibroblasts (BCFFs) with retroviruses carrying defined factors (OCT4, SOX2, KLF4, c-MYC and EGFP; OSKMG) in the presence of VPA. Cells were collected (Day 7) and analyzed using RNA-seq technology. Afterwards, different groups of cells and transcriptomics results were detected by PCR and qRT-PCR technology. The results showed that VPA promoted the expression of the endogenous gene c-Myc and inhibited cell proliferation; at the same time, it promoted the expression of VEGF and other genes related to angiogenesis.

Conclusions: When VPA is added to the culture medium, only the cells that have begun to reprogram can break the G2/M repression through the expression of the endogenous gene c-Myc, and use the nutrients and space in the culture dish to proliferate normally, which can achieve the purpose of directly improving the efficiency of reprogramming. Another new discovery for Bactrian camels, VPA significantly increased the expression of VEGFC and other genes, promoting the transformation of fibroblasts to endothelial cells (different from the mesenchymal-to-epithelial transition process of other species) to accelerate the early induction of Bactrian camels iPSc process. Overall, this study proved the new mechanism of VPA in enhancing the induction of pluripotency from the transcriptome level.
\end{abstract}

Keywords: Induced pluripotent stem cells, Bactrian camel, Valproic acid, RNA-seq

Received: December 26, 2020, Revised: January 15, 2021,

Accepted: January 17, 2021, Published online: February 28, 2021

Correspondence to Yong Zhang

Department of Veterinary Obstetrics, College of Veterinary Medicine, Gansu Agricultural University, No. 1, Yingmen Village, Anning District, Lanzhou 730070, China

Tel: +86-13893126652, Fax: +86-09317631229

E-mail: zhangyong@gsau.edu.cn

(a) This is an open-access article distributed under the terms of the Creative Commons Attribution Non-Commercial License (http://creativecommons.org/ licenses/by-nc/4.0/), which permits unrestricted non-commercial use, distribution, and reproduction in any medium, provided the original work is properly cited.

Copyright (C) 2021 by the Korean Society for Stem Cell Research

\section{Introduction}

Induced pluripotent stem cells (iPSCs) are generated through the transfection of embryonic mouse fibroblasts with retroviruses carrying four factors (Oct4, Sox2, Klf4, and c-Myc; OSKM) (1) thereby reprograming them into a class of cells that had similar pluripotency features to those of embryonic stemcells. Thus far, iPSCs have been successfully generated from humans and a wide range of animals, including mice, rats, rabbits, pigs, sheep, cattle, horses and monkeys (2-10). However, there have been no reports of Bactrian camel iPSCs to date. Bactrian camel arean endemicspecies that reside in desert and semi-desert 
regions (11). Bactrian camels are exceptionally adept at tolerating wide temperature variations and have a remarkable ability to continuously go without water for months. These animals are quite useful for humans as they were domesticated in ancient times and have thereafter served as pack animals in places like inner Asia. As such, studiesaimed towards protecting the germplasm resources of these animals and generating iPSCs are warranted (11, 12).

The small molecule compound valproic acid (VPA) is a histone deacetylase (HDACs) inhibitor, that can significantly improve the induction efficiency and maintain the stability of iPSCs $(13,14)$. The addition of VPA during IPSC induction can significantly improve the reprogramming efficiency (more than 100 times) (15). Moreover, the presence of this compound allowed the successful reprogramming of human fibroblasts to iPSCs using only Oct4 and Sox2 (16). Despite the confirmation of the role of VPA inpromoting cell reprogramming and increasing the induction efficiency of iPSCs by inhibiting genes encoding cell cycle regulatory elements, such asp35, $\mathrm{p} 21, \mathrm{p} 18, \mathrm{p} 17$, and $\mathrm{p} 16$, and senescence signaling pathways (17), the underlying mechanisms these phenomena remain unclear.

Based on previous work, our laboratory adopted an RNA-seq approach to analyze the early role of VPA during the early induction of Bactrian camel iPSCs. Here, we aimed to provide a better understanding of the role of VPA and the molecular mechanism involved inthe early induction of iPSCs.

\section{Materials and Methods}

\section{Plasmid preparation}

PMXS-Oct4, PMXS-Sox2, PMXS-Klf4, and PMXS-cMyc plasmids carrying the defined murine-sourced factors were prepared and stored in our laboratory along with the pCMV-VSV-G and pUMVC plasmids, which were used for viral packaging. Using the EGFP gene as a template, we designed primers which were then cloned and ligated into the HindIII / BamHI site of the PMXS plasmid to achieve the PMXS-EGFP plasmid containing a reporter gene.

\section{Cell lines and cell culture conditions}

The highly transfectable 293T cells were donated by the Lanzhou Veterinary Research Institute of the Chinese Academy of Sciences. The cells were cultured in DMEM/ high glucose (Hyclone) supplemented with 10\% fetal bovine serum (FBS; $\mathrm{BI}$ ) and maintained at $37^{\circ} \mathrm{C}$ in an atmosphere containing $5 \% \mathrm{CO}_{2}$.
All experimental procedures were approved by the Animal Care and Use Committee of the College of Veterinary Medicine at Gansu Agricultural University (Approval No: GSAU-AEW-2017-0003). Bactrian camel fetal fibroblasts (BCFFs) were derived from three-month-old Bactrian camel fetuses and cultured (tissue block adherent culture) after digestion and separation (18). The cells were maintained at typical cell culture conditions $\left(37^{\circ} \mathrm{C}, 5 \%\right.$ $\mathrm{CO}_{2}$ ) in DMEM/F12 glucose (Hyclone) supplemented with $10 \%$ FBS. Cells were subcultured once they reached $90 \%$ confluency. The first three generations of BCFFs were frozen.

\section{Retroviral infection and VPA processing}

To begin with, 293T packaging cells were plated at $1 \times 10^{6}$ cells per $60 \mathrm{~mm}$ dish and incubated overnight. Then, lipofectamine 2000 (Invitrogen, CA) was used to package and generate five retroviruses (OCT4, SOX2, KLF4, c-MYC and Gfp; OSKMG) in a certain manner for subsequent induction of iPSC $(19,20)$. Following a 48-h transfection, the medium was collected as the first virus-containing supernatant and replaced with a new medium, which was collected after 72 -h as the second virus-containing supernatant.

BCFFs were first plated into six-well plates $\left(2 \times 10^{5}\right.$ cells/well) one day before transduction. After which the virus-containing supernatants were filtered through a 0.45 $\mathrm{mm}$ pore-size filter and supplemented with $8 \mathrm{mg} / \mathrm{ml}$ polybrene. Equal amounts of supernatants containing each of the five retroviruses were mixed and transferred to the fibroblast dishand incubated overnight. Following 24-h transduction, the virus-containing medium was replaced with the second supernatant.

Next, the cells were randomly divided into two groups: controland treatment. After two transductions, the culture medium was replaced with an iPSC induction medium, composed of knockout DMEM/F12 medium (Gibco) supplemented with $20 \%$ knockout serum replacement (Gibco), $2 \mathrm{mmol} / 1$ nonessential amino acids (NEAA, Gibco), 0.1 mmol/1 $\beta$-mercaptoethanol (Sigma-Aldrich), $20 \mathrm{ng} / \mathrm{ml} \mathrm{FGF2}$ (Thermo), and $10 \mathrm{ng} / \mathrm{ml}$ leukemia inhibitory factor (LIF, Thermo); the cells in the treatment group we additionally supplemented with $1 \mathrm{mM}$ valproic acid (VPA). Moreover, all the cells were fed with fresh iPSC culture medium daily, and samples were collected after seven days by trypsinization (15) and then snap-frozen in liquid nitrogen and stored at $-80^{\circ} \mathrm{C}$ until further use.

\section{Transcriptome sequencing and analysis}

The three replicates of the control group were randomly 
named CK-1, CK-2, and CK-3; whereas, the three replicates of the treatment group were randomly named $\mathrm{T}-1$, T-2, T-3. Cell samples were sent to a RNA-seq sequencing company on dry ice and a cDNA library was established. The cDNA library was sequenced, using paired-end technology, on the Illumina sequencing platform (Illumina HiSeq $^{\mathrm{TM}}$ 2500) by Genedenovo Biotechnology Co., Ltd (Guangzhou, China). The fastp (21) (https://github.com/ OpenGene/fastp) program was written to select clean reads by removing low-quality sequences (there were more than $50 \%$ bases with quality lower than 20 in one sequence), reads with more than $10 \% \mathrm{~N}$ bases (bases unknown) and those reads containing adaptor sequences.

HISAT2 (22) was used for alignment of RNA sequencing readsand the Camelus bactrianus Ca_bactrianus MBC_1.0 genome assembly (https://www.ncbi.nlm.nih. gov/genome/?term=Camelus + bactrianus) was used as the reference genome. Then, based on the gene expression information, we used R (http://www.r-project.org/) to carry out principal component analysis (PCA) and calculate the Pearson correlation coefficients. After that, differential gene expression analysis was performed using the DESeq2 (23) software and the related pathways were investigated using KEGG (http://www.kegg.jp/) and GO (http://geneontology.org/) analyses. Further, the interaction and relationship between proteins of interest were analyzed using the STRING protein interaction database (http://string-db. org) and a differential gene protein interaction network was established.

Gene set enrichment analysis (GSEA) was also performed as it can effectively make up for the common problems faced during traditional enrichment analyses, such as insufficient mining information of effective genes, and can more comprehensively explain the regulatory role of a functional unit (KEGG pathway, GO term or other).

\section{qRT-PCR validation}

Total RNA was extracted from cells using TRIzol reagent (Sigma, USA) according to the manufacturer's protocol (24) and then stored at $-80^{\circ} \mathrm{C}$ until further use. The cDNA was prepared using the RevertAid ${ }^{\mathrm{TM}}$ First Strand cDNA Synthesis Kit (Thermo Fisher Scientific Inc., USA) following the manufacturer's protocol (25). After that, qRT-PCR was performed to identify the expression patterns of selected genes (Table 1) in the two groups. To amplify fragments corresponding to the selected genes, primers were designed using the NCBI Primer-BLAST tool. We used $\beta$-Actin (Table 1) as an internal control to normalize the expression level of the target genes. In preparation for the qRT-PCR, a $20 \mu 1$ reaction volume con- taining $10 \mu 1$ of the Real Master Mix SYBR, $8 \mu 1$ of $\mathrm{ddH}_{2} \mathrm{O}, 1 \mu \mathrm{l}$ each of the forward and reverse primers, and $1 \mu 1$ of cDNA was prepared. All samples were amplified in triplicate and the mean and standard error values were calculated. Relative expressions of all genes were calculated using the $\triangle \Delta \mathrm{CT}$ method.

\section{Detection of reprogramming progress}

We named the untreated BCFFs, the blank group with four OSKM genes. No VPA was named OSKM, and the treatment group with VPA was named OSKM+VPA. To prove that the cells in the experiment initiated reprogramming, we performed the following tests. The expression of foreign genes (Table 1) in the three groups was detected by PCR to demonstrate that the foreign genes were successfully transferred. In the early stages of cell reprogramming, the expression of the marker genes (Table 1) of the three germ layers will change, so we prove that the reprogramming has started by detecting the expression of the specific expression genes (Table 1) of the stem cells and the expression of the three germ layer marker genes.

\section{RNA-seq data analysis}

Following verification of the RNA-seq data credibility and initiation of reprogramming, we combined the current research results. We further screened the selected signaling pathways related to the iPS and cancer signaling pathways and found that the final result pointed to the cell cycle and endothelial cell production. We then visualized the relevant genes using heatmaps and verified our analyses using qRT-PCR.

\section{Results}

\section{VPA treatments}

To study the role of VPA in the reprogramming of BCFFs, we used 293T cells to package retroviral vectors containing Oct4, Sox2, Klf4, c-Myc, and EGFP. Following viral transduction, the EGFP retroviral packaging results (Fig. 1B) were used to predict the packaging efficiency of the remaining four retroviruses. In short, the five retroviruses were mixed in equal proportions andused to transduce pre-plated BCEFs. After the second retroviral infection, the medium of the CEF cells was replaced with an iPSC medium, supplemented with $1 \mathrm{mM} \mathrm{VPA}$ in the treatment group (Fig. 1A). The infection efficiency was observed 48-h after the second viral infection (Fig. 1C). Finally, seven days after VPA treatment, the cell status was observed under an optical microscope and the cells were collected for further analysis (Fig. 1D). 
Table 1. The primers list of PCR

\begin{tabular}{|c|c|c|c|}
\hline Gene & Primer & Annealing temperature $\left({ }^{\circ} \mathrm{C}\right)$ & Fragment size (bp) \\
\hline \multirow[t]{2}{*}{ Oct4 } & СТСТTGТСТАССТСССТTGСС & 57 & 100 \\
\hline & TCTGTTCCСGTCACTGCTCT & & \\
\hline \multirow[t]{2}{*}{ Sox 2} & GGTGСССТGCTGCGAGTA & 57 & 360 \\
\hline & CGGCGGAAAACCAAGACG & & \\
\hline \multirow[t]{2}{*}{ Klf4 } & CGTTGAACTCCTCGGTCTCC & 57 & 170 \\
\hline & CGACTAACCGTTGGCGTGA & & \\
\hline \multirow[t]{2}{*}{ c-Myc } & GGACTGTATGTGGAGCGGTTTC & 57 & 487 \\
\hline & TGGGCTGTGCGGAGGTTT & & \\
\hline \multirow[t]{2}{*}{ nSox2 } & AGAGAACCCCAAGATGCACA & 57 & 104 \\
\hline & GCTTGGCCTCGTCGATAAAC & & \\
\hline \multirow[t]{2}{*}{ nKIf4 } & TCCCGGGGATTCATAGTTCG & 57 & 310 \\
\hline & GGGCAAACTTCCATCCACAG & & \\
\hline \multirow[t]{2}{*}{ TEAT } & AGAAGCTAGTCTCCСTGGGA & 57 & 174 \\
\hline & CCATCAACCAGCACAGGAAC & & \\
\hline \multirow[t]{2}{*}{ CRABP2 } & AGCAAACTGTGGATGGGAGA & 55 & 168 \\
\hline & CGATGTCATCTGCСGTCATG & & \\
\hline \multirow[t]{2}{*}{ NCSTN } & СССТTСАGСАТTAСАТСGСС & 55 & 167 \\
\hline & AACCCACGCGTACTCATACA & & \\
\hline \multirow[t]{2}{*}{ DES } & CCATCGCGGCTAAGAACATC & 55 & 184 \\
\hline & GAATCGTTGGTGCCCTTGAG & & \\
\hline \multirow[t]{2}{*}{ PAX6 } & TCAGCACCAGTGTCTACCAG & 55 & 243 \\
\hline & AGGTATCATAACTCCGCCCG & & \\
\hline \multirow[t]{2}{*}{ PTGS2 } & GCTGCGGGAACACAATAGAG & 53 & 249 \\
\hline & TGCCAGTGGTAGAGTGTGTT & & \\
\hline \multirow[t]{2}{*}{ MMP9 } & GCAAACCAATCTCACCGACA & 53 & 223 \\
\hline & GGTCAGAAATTTGCCCACGT & & \\
\hline \multirow[t]{2}{*}{ CCNB1 } & AGCGGATCCCAACCTTTGTA & 53 & 248 \\
\hline & GCATCTTCTTGGGCACACAA & & \\
\hline \multirow[t]{2}{*}{ CCNB2 } & AGTACCTGAGGCAGCTTGAG & 53 & 231 \\
\hline & GCAGAGCTGTAATCCCAACC & & \\
\hline \multirow[t]{2}{*}{ CXCL8 } & GTGAAGCTGCAGTTCTGTCA & 53 & 151 \\
\hline & ССТСТСТTССАТTGGСАAGC & & \\
\hline \multirow[t]{2}{*}{ IGFBP3 } & GCCAGCGCTACAAAGTAGAC & 53 & 209 \\
\hline & GCGGCACTGTTTCTTCTTGT & & \\
\hline \multirow[t]{2}{*}{ CCNA2 } & AGGAGAACATCAACCCCGAG & 53 & 179 \\
\hline & GGGAGGAACAGTGACATGCT & & \\
\hline \multirow[t]{2}{*}{ PLK1 } & CTCGACACGССТTATCСТCT & 53 & 206 \\
\hline & GGGCTAGCTCATCACCTTCA & & \\
\hline \multirow[t]{2}{*}{ VEGFC } & СТСТСТСТСАAGGССССААА & 53 & 244 \\
\hline & GGGTCATCTCCAGCGTTAGA & & \\
\hline \multirow[t]{2}{*}{ CKS2 } & GACAAGTACTTCGACGAGCAC & 53 & 167 \\
\hline & TGTGGTTCTGGCTCATGAATC & & \\
\hline RRM2 & TGCСТGССТGATGTTCAAAC & 53 & 182 \\
\hline & GCATAAGTCTGTCTGCCACG & & \\
\hline CDC20 & AGAATCAGCCCGAAAACAGC & 57 & 220 \\
\hline & AGGGAAGGAATGTAACGGCA & & \\
\hline TP3 & GAGGACGCCAGTGGTAATCT & 56 & 197 \\
\hline & AGCGGCTTCTTCTTTTGTGG & & \\
\hline IFK67 & CCGTCATACCCAGCAGTGAA & 56 & 208 \\
\hline & CCTGGCGCTTTCTGGAATTT & & \\
\hline PCNA & CGGACACCTTGGCACTAGTA & 56 & 215 \\
\hline & САССССАТСТTTTGCACAGG & & \\
\hline
\end{tabular}


Table 1. Continued

\begin{tabular}{|c|c|c|c|}
\hline Gene & Primer & Annealing temperature $\left({ }^{\circ} \mathrm{C}\right)$ & Fragment size $(b p)$ \\
\hline \multirow[t]{2}{*}{ CASP7 } & TCСТCTTTTGTCССАTСGCT & 56 & 198 \\
\hline & CTCGGCGTCTTTGTCTGTTC & & \\
\hline \multirow[t]{2}{*}{ S100A4 } & TTCСАСАAGTACTCGGGCAA & 56 & 242 \\
\hline & TTATCCGGGAAGCCTTCGAA & & \\
\hline \multirow[t]{2}{*}{ VIM } & GATTCAGGAACAGCACGTCC & 56 & 207 \\
\hline & TTGGATTCTTGCTTCGССTG & & \\
\hline \multirow[t]{2}{*}{ HSP47 } & CACTACAACTGCGAGCACTC & 56 & 220 \\
\hline & CCATGAAGCCTCGATTGTCC & & \\
\hline \multirow[t]{2}{*}{ ACTA2 } & TCTGGACGTACAACTGGCAT & 56 & 195 \\
\hline & GACAATCTCACGCTCAGCAG & & \\
\hline \multirow[t]{2}{*}{ ICAM1 } & TGATACCCTCCGGATTGTGG & 56 & 247 \\
\hline & ATTCTCCAGTCTACTCCGCG & & \\
\hline \multirow[t]{2}{*}{ LYVE1 } & ACAAACCCGCAGCTGAATTT & 56 & 175 \\
\hline & ACTTGGGGTTCGCGAAAATC & & \\
\hline \multirow[t]{2}{*}{ CLDN7 } & TGGCCACCAGATAGTCACAG & 56 & 172 \\
\hline & TGCACGATACCCAGTTTTGC & & \\
\hline \multirow[t]{2}{*}{ EPCAM } & AAACTGCTCTTTGAACGCGT & 56 & 204 \\
\hline & AGССССТTСТСАТСАСАGTC & & \\
\hline \multirow[t]{2}{*}{$\mathrm{CDH} 1$} & AGAGAACTTGGAGCACGTGA & 56 & 229 \\
\hline & AAAGGGAGACGTGTTAGGGG & & \\
\hline
\end{tabular}

\section{A.Reprogramming}

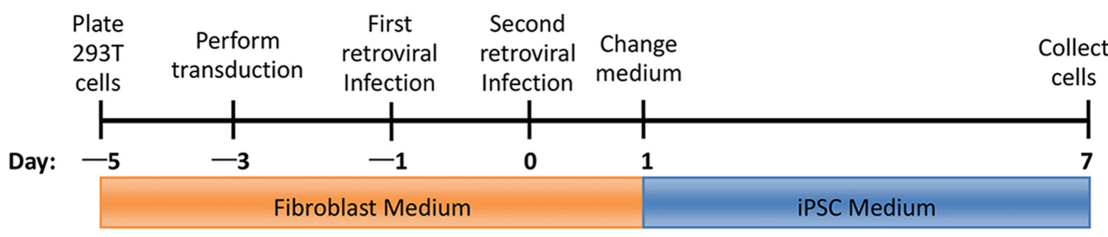

\section{B.48h after transfection}

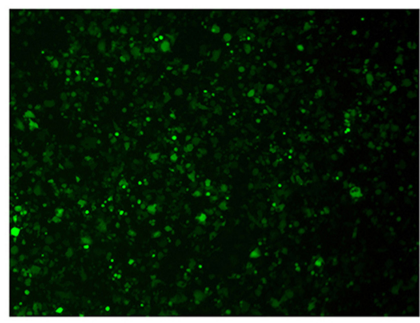

$293 \mathrm{~T}$ cell

D. 7 day after infection

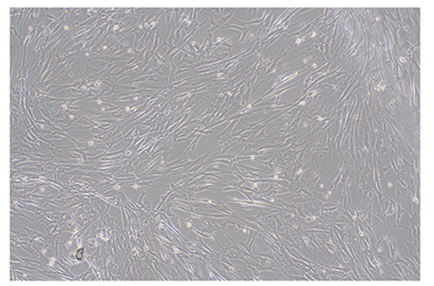

Control
C. $48 \mathrm{~h}$ after infection

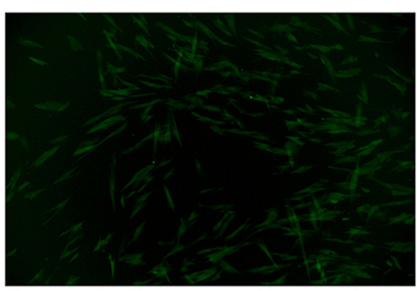

CEF cell

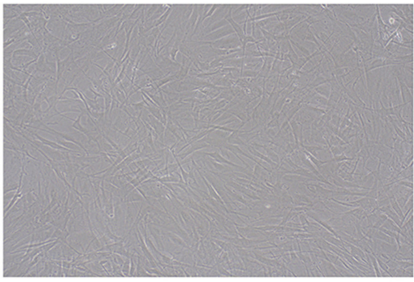

Add VPA
Fig. 1. VPA cell treatments. (A) Schematic diagram of iPSC culture medium containing VPA. (B) The EGFP retroviralpackaging 48-h after transduction. (C) The infection efficiency in CEFs was observed 48-h after the second viral infection. (D) Cells in the treatment (iPSC medium with VPA) and control (iPSC medium without VPA) groups were cultured in the iPSC medium on day 7. 


\section{Dynamic changes of processed cells}

To verify whether the reprogramming factors were successfully transferred into and modified BCFFs, we used PCR to detect the expression of the four exogenous genes Oct4, Sox2, Klf4 and c-Myc in the three groups (Table 1). We found that the four genes of OSKM were successfully transferred and expressed (Fig. 2A). We then selected three endogenous genes (Table 1) that were only expressed at the stage of pluripotent stem cells for PCR detection and generated heat maps of the four endogenous genes based on the sequencing data. Except for BCFFs, the endogenous genes of the other two groups were all expressed (Fig. 2B), and the addition of VPA increased the expression of the Myc gene (Fig. 2C). We also tested the expression of the marker genes (Table 1) of the three germ layers in the three groups of cells during stem cell differentiation. The results showed that the expression of PAX6 and CRABP2 (ectoderm) in the OSKM and OSKM +VPA groups was significantly increased (Fig. 2D), and PAX6 was specifically expressed (Fig. 2E).

These results indicate that the treated cellsinitiated the reprogramming process, and that VPA promotes the expression of endogenous Myc and ectoderm genes in the three germ layers.

\section{Transcriptomic sequencing, basic analysis of correlations and differences between groups}

To identify the role of VPA in the reprogramming of $\mathrm{CEFs}$, we conducted transcriptomic profiling of a total of six samples from the treatment and control groups using RNA-seq. Based on the obtained gene expression profiles of each sample, we used PCA to analyze and calculate the Pearson correlation coefficient (Fig. 3A) between samples to understand the repeatability of the samples and exclude outliers. Based on the differential analysis results, after seven days of VPA treatment, we considered genes with FDR $<0.05$ and $\mid \log 2$ FC $\mid>1$ as significantly differentially expressed genes. A total of 959 genes were expressed early in the reprogramming process, of which 469 genes were upregulated and 490 were downregulated. Each gene was z-score processed and hierarchical clustering of differential gene expression patterns was performed; the clustering results are represented as a heat map (Fig. 3B).

Next, significant pathways were analyzed using KEGG pathway enrichment analysis and hypergeometric tests to identify pathways that were significantly enriched in genes of interest compared to the entire genome background. KEGG pathway-based analyses help to determine the most important biochemical metabolic pathways and signal

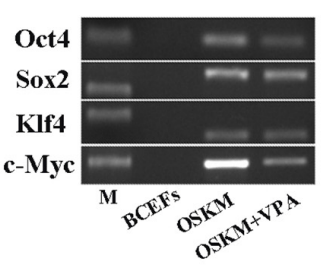

A

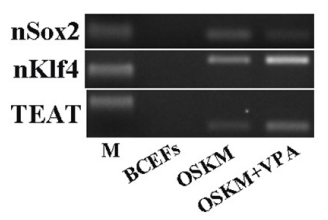

B

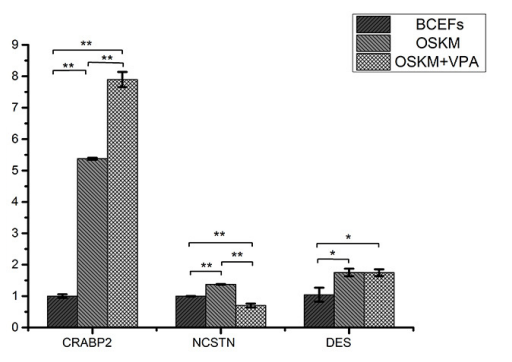

D

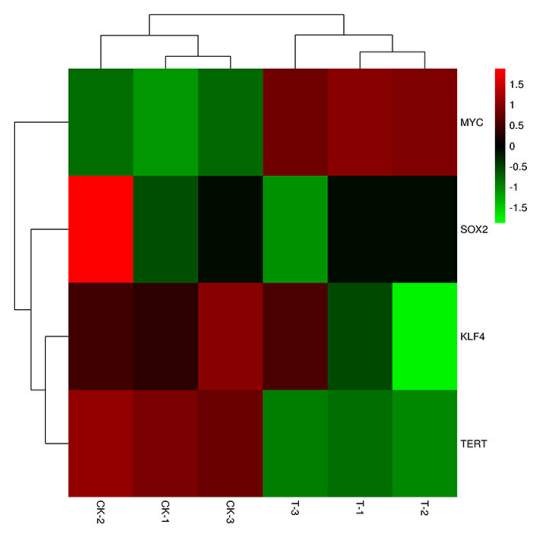

C

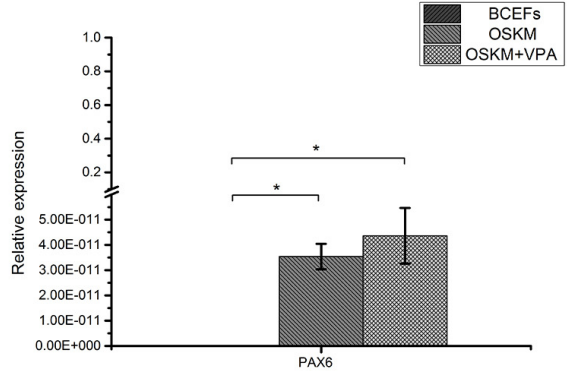

$\mathbf{E}$
Fig. 2. Dynamic changes of processed cells. (A) Detection of the expression of exogenous genes in the three groups of BCFFs, OSKM and OSKM+VPA. (B) Detection of the expression of endogenous genes in the three groups of BCFFs, OSKM and OSKM+VPA. (C) Heat map of the four endogenous genes. (D, E) The expressions of the three germ layer genes NCSTN (endoderm), DES (mesoderm), PAX6 and CRABP2 (ectoderm) were detected by qRT-PCR. 


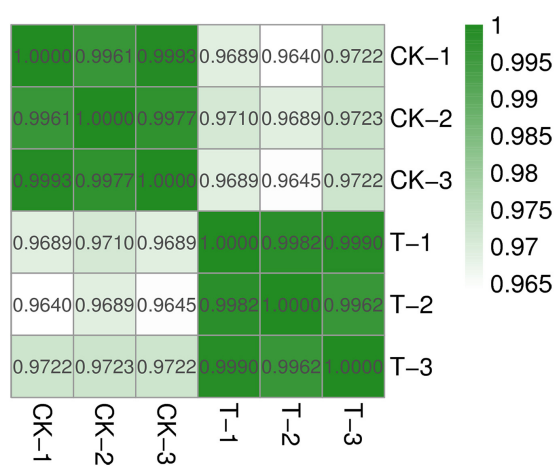

A

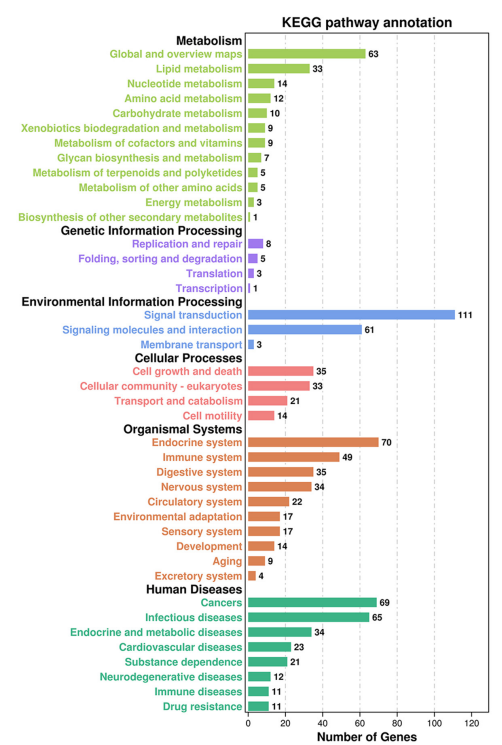

C
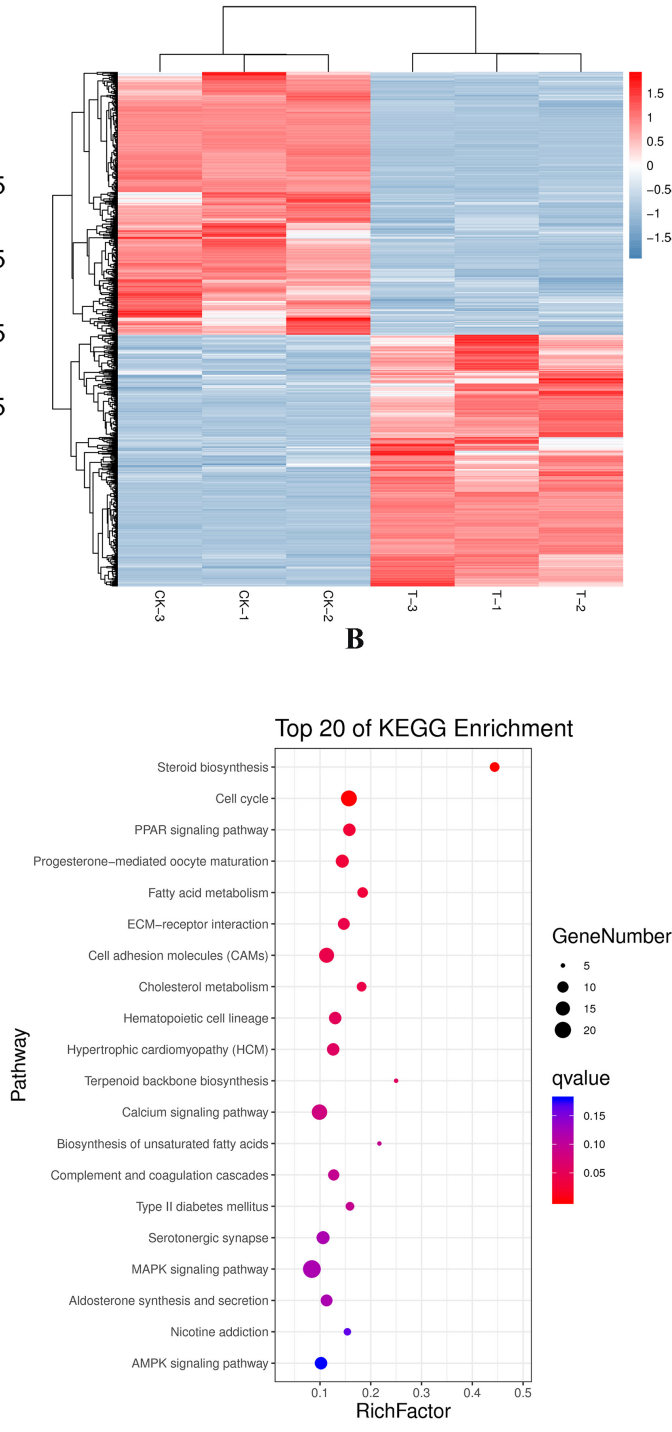

D
Fig. 3. Transcriptomic sequencing, basic analysis of correlations, and differences between groups. (A) Correlation heat map of the samples. In the figure, the abscissa and ordinate are the respective samples and the color depth (intensity) indicates the correlation coefficient between the two samples. (B) Genes from different samples are expressed in different colors; the redder the color, the higher the expression; whereas, the bluer the color, the lower the expression. (C) KEGG pathway annotation. The map is plotted with different pathways and the number of target genes contained within. The pathways belonging to the same KEGG A-class classification share the same color. Each pillar represents a pathway and the height of the pillar represents the number of genes involved in each pathway. (D) Top 20 genes obtained after KEGG enrichment analysis. Each bubble represents a pathway; the size of the bubble represents the number of target genes contained in the pathway and the color of the bubble represents the significant degree of enrichment of the pathway. transduction pathways that were related to unigenes. The enrichment results were classified accordingly as A and B grades (Fig. 3C) and signaling pathways were determined. By combining these findings with RNA-seq data, we selected 959 differentially expressed genes, enriched in 276 signaling pathways. In total, there were eight signal pathways with a $\mathrm{Q}<0.05$ and 42 signal pathways with a $\mathrm{p}<$ 0.05 . Notably, the eight signal paths were steroid biosynthesis, cell cycle, PPAR signaling pathway, progesterone-mediated oocyte maturation, fatty acid metabolism, ECM-receptor interaction, cell adhesion molecules (CAMs) and cholesterol metabolism. Finally, we used the top 20 signal paths for mapping (Fig. 3D).

\section{Individual key pathways involved in BCFF reprogramming}

Considering that iPSCs and cancer cells share similar features, we adopted an RNA-seq approach to select eight signaling pathways, of the 276 related to cancer and iPSCs, for analysis (Table 2). We used the important enzymes in the above-mentioned eight and an additional eight key signal pathways with a $\mathrm{Q}<0.05$ to construct a protein-protein interaction (PPI) network using the interactive gene retrieval tool (STRING); the obtained PPI network contained 135 enzymes from the above-mentioned signal transduction pathway enzymes (Fig. 4A). According to the ppi network, 12 genes (Table 1) at the core were selected to verify the credibility of the RNA-seq data through qRT-PCR. Results obtained using qRT-PCR (Fig. 4B) were compared to data obtained by RNA-seq; notably, 
the expression patterns for the 12 genes obtained using the two methods were consistent, confirming the reliability of RNA-seq technology.

After verifying the RNA-seq data, we conducted further analysis of the eight selected pathways related to iPS and cancer. According to the ranking, we excluded the TGF- $\beta$, Wnt, and Jak-STAT signaling pathways. We selected the

Table 2. iPSC and cancer-related signaling pathways

\begin{tabular}{lcc}
\hline \multicolumn{1}{c}{ Pathway } & ID & Ranking \\
\hline Cell cycle & ko04110 & 2 \\
MAPK signaling & ko04010 & 17 \\
PI3K-Akt signaling & ko04151 & 26 \\
Pathways in cancer & ko05200 & 27 \\
p53 signaling & ko04115 & 52 \\
TGF- $\beta$ signaling & ko04350 & 209 \\
Wnt signaling & ko04310 & 234 \\
Jak-STAT signaling & ko04630 & 263 \\
\hline
\end{tabular}

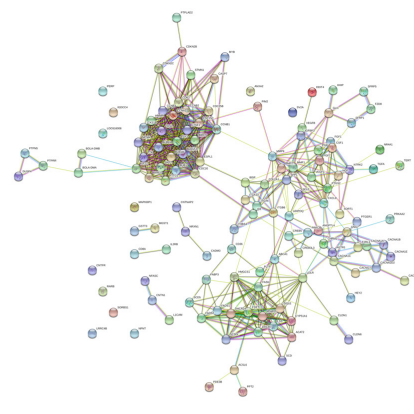

A key genes of the MAPK and PI3K-Akt signaling pathways and generated heat maps (Fig. 4C). The results showed that although the expression of some genes increased, it was not significant. We selected the enriched genes and p53 genes in the p53 signaling pathway to make a heat map (Fig. 4D). At the same time, qRT-PCR was used to detect the expression of P53 gene (Table 1) in the three groups of BCFFs, OSKM and OSKM+VPA (Fig. 4E). The results showed that the four factors of OSKM significantly inhibited the p53 expression after cell transfer, however, VPA did not directly act on the p53 gene. It only inhibited the expression of downstream genes in this pathway.

\section{Effects on proliferation and apoptosis-related genes}

The cell cycle progression was one of the main obstacles that affect cell reprogramming, cell proliferation and apoptosis. We generated a heat map of the genes in the

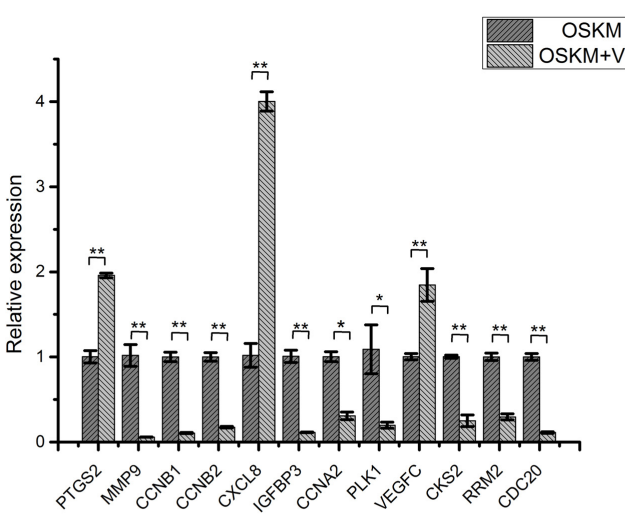

B

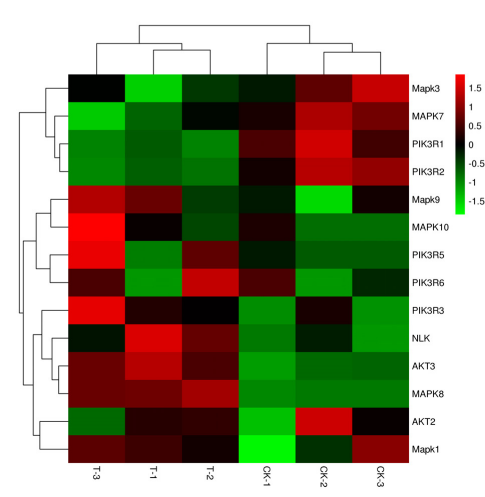

C

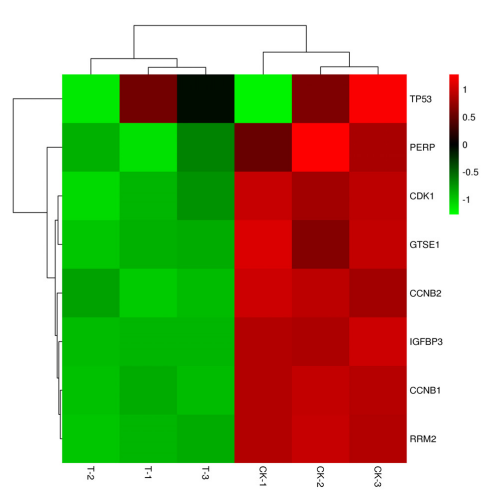

D

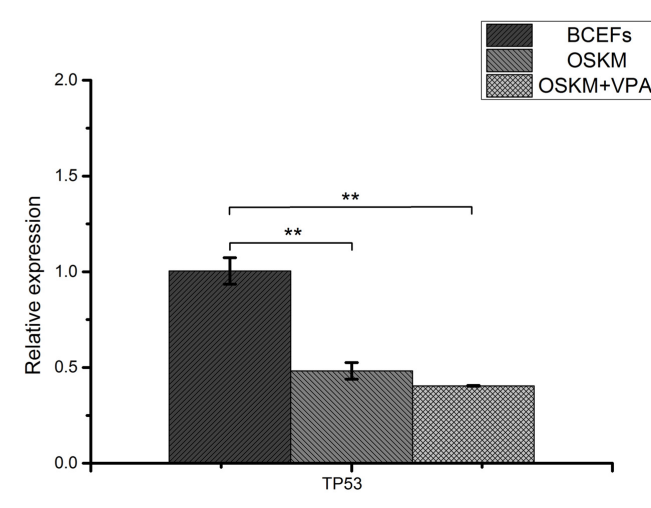

$\mathbf{E}$

Fig. 4. Participate in the screening of key pathways for reprogramming of BCFFs. (A) Represents a protein-protein interaction network made according to different requirements. Different nodes represented different enzymes. The interactions among these enzymes were represented by different colorful lines. (B) Twelve genes were verified by qRT-PCR. (C) Heat map of key genes of the PI3K-Akt and MAPK signaling pathways. (D) Heat map of key genes of p53 signaling pathway. (E) TP53 gene expression was detected by qRT-PCR. 
Cell cycle pathway (Fig. 5A); and compared the changes in proliferation and apoptosis genes (Table 1) in the three groups of BCFFs, OSKM and OSKM+VPA (Fig. 5B). The results show that VPA has an inhibitory effect on cell cycle signaling pathways, stagnating cells in $\mathrm{S}$ phase, unable to divide. VPA also promotes the expression of apoptosis genes and inhibits the expression of proliferation genes. Therefore, we speculate that one of the roles of VPA in the cell reprogramming process is to screen out successfully reprogrammed cells by promoting cell apoptosis and inhibiting cell proliferation.

\section{The influence of VPA on the mesenchymal-to-epithelial transition process}

Given that iPS cells and cells have many similarities, we have done heat maps for all genes enriched in cancer signaling pathways (Fig. 6A). We found that genes overexpressed in this signaling pathway predominantly affects the VEGFC signaling pathway. The activation of this pathway leads to the upregulation of genes involved in mediating the proliferation and migration of endothelial cells and promoting their survival and vascular permeability.

This result makes us pay attention to the changes of cell

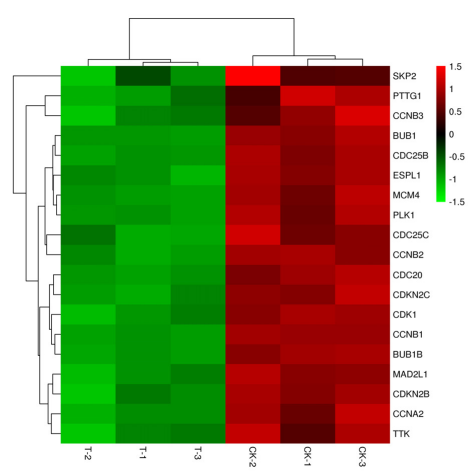

A
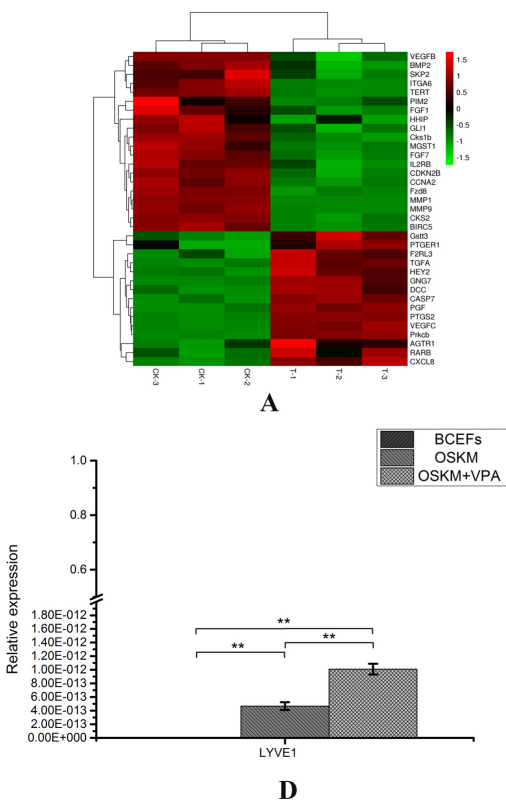

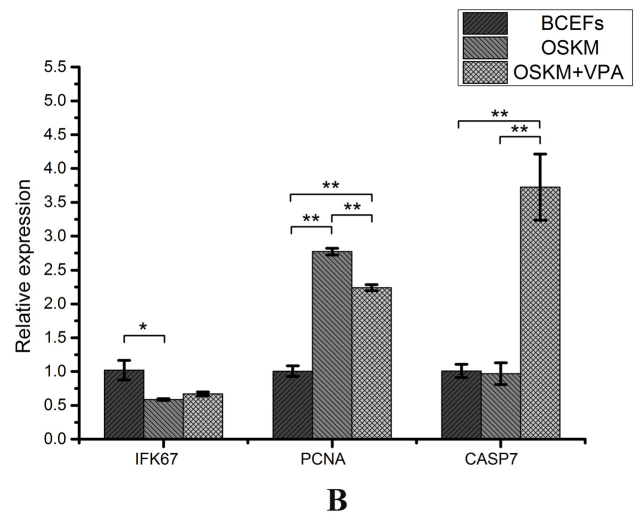

Fig. 5. Effects on proliferation and apoptosis genes. (A) The heat map made using enriched genes in cell cyclesignaling pathways. (B) The changes of proliferation and apoptosis genes in the three groups of BCFFs, OSKM and OSKM+VPA.

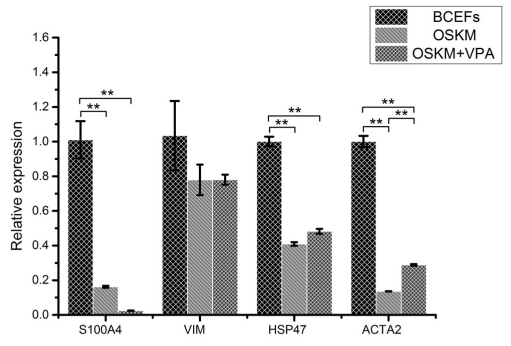

B

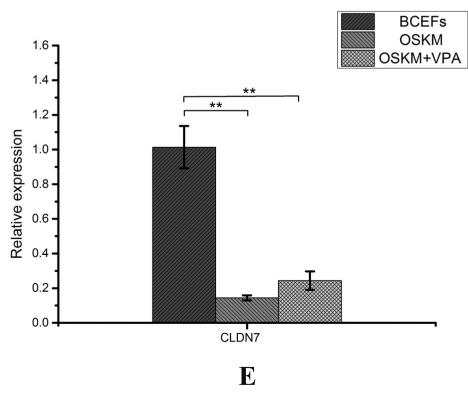

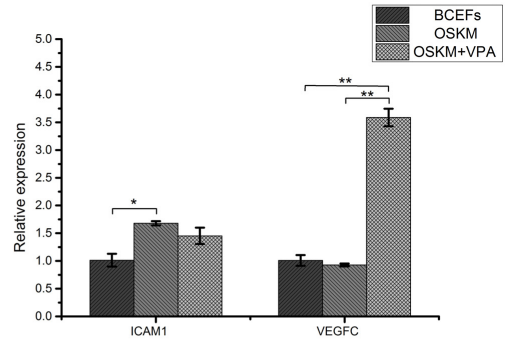

C

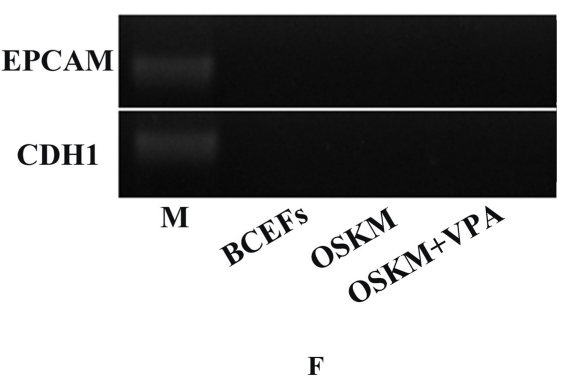

Fig. 6. The influence of VPA on the mesenchymal-to-epithelial transition process. (A) The heat map made using enriched genes in cancer signaling pathways. (B) The results of qRT-PCR detection of the expression of fibroblast marker genes S1004A, VIM, HSP47 and ACTA2 in the three groups of BCFFs, OSKM and OSKM+VPA. (C, D) The results of qRT-PCR detection of the expression of endothelial cell marker genes ICAM1, VEGFC and LYVE1 in the three groups of BCFFs, OSKM and OSKM+VPA. (E) The qRT-PCR results of the expression of the epithelial cell marker gene CLDN7 in the three groups of BCFFs, OSKM and OSKM+VPA. (F) PCR detection of the expression of epithelial cell marker genes EPCAM and $\mathrm{CDH} 1$ in the three groups of BCFFs, OSKM and OSKM+VPA. 
types in cell culture dishes, which may involve another important event in the iPS induction process-mesenchymal-to-epithelial transition (MET). Although endothelial cells are a type of epithelial cells, there are still certain differences between the two. We selected four fibroblast marker genes (Table 1), four endothelial cell marker genes (Table 1) and three epithelial cell marker genes (Table 1) for qRT-PCR. After testing, we found that the expression of fibroblast marker genes in the OSKM and OSKM+ VPA groups decreased significantly (Fig. 6B). The marker genes of endothelial cells were significantly increased (Fig. 6C), and the two marker genes of epithelial cells were not expressed (Fig. 6F). We observed that the addition of VPA promotes the expression of CLDN7 (epithelial cells; Fig. 6E), VEGFC and LYVE1 (Fig. 6D; endothelial cell genes), and affects the expression of fibroblast marker genes. Therefore, we determined that for Bactrian camels, VPA promoted the conversion of fibroblasts to endothelial cells instead of directly converting to epithelial cells, which is different from the MET process of other species.

\section{Discussion}

Some studies have indicated the potential of VPA as a replacement for c-Myc for achieving complete reprogramming of mouse fibroblasts (15); VPA can even replace both Klf4 and c-Myc to successfully reprogram human fibroblasts into iPSCs (26). More importantly, VPA significantly improves the iPSC induction efficiency (26-28). However, little is known about its mechanism of action.

To explore the mechanism of VPA, the majority of research focus has been on important genes and related signaling pathways in the induction of iPS cells. The activation of the Wnt signaling pathway can demethylate the promoter regions of the pluripotency genes Oct4 and Nanog (29), significantly promoting the induction efficiency of iPS cells. The activation of JAK/STAT signaling pathway is very important to maintain the self-renewal ability of stem cells (30). The inhibition of the MAPK and GSK3 signaling pathways can effectively improve the synchronization of iPS cell induction, and promote the proliferation and formation of iPS cells (31-33). Inhibition of TGF- $\beta$ signaling pathway can promote the induction of iPS cells (33). PI3K-Akt signaling pathway can regulate cell growth, proliferation, differentiation and cell survival; this pathway is activated in cancer cells (34). The cell cycle regulator p53 prevents cells from uncontrolled proliferation due to DNA damage; knocking out the p53 gene or inhibiting the related signaling pathway can promote the induction of iPS cells $(35,36)$.
Here, we used RAN-Seq sequencing technology for the first time on the role of VPA in the early process of iPSc induction. We conducted an in-depth analysis of the RNA-Seq results based on the current research results and found that: 1) The addition of VPA significantly promoted the expression of endogenous c-Myc, and c-Myc was mainly bound to the promoter area, playing a role in promoting cell survival and proliferation in the early stages of reprogramming $(37,38)$; 2) VPA has a significant inhibitory effect on cell cycle signaling pathways, especially CDK and CDC genes in G2 and S phases; 3) VPA significantly promotes the expression of VEGFC and other genes in the cancer signaling pathway, and these genes activate the VEGF signaling pathway.

In conclusion, we determined that the role of VPA is a complicated process in the early stage of Bactrian camel iPSc induction. However, it can be summarized in two aspects: 1) VPA can significantly inhibit the cell circulation pathway to make cells stay in the $\mathrm{G} 2 / \mathrm{M}$ phase, and significantly increase the expression of the endogenous gene c-Myc. So theoretically, when VPA is added to the culture medium, only the cells that have begun to reprogram can break the $\mathrm{G} 2 / \mathrm{M}$ repression through the expression of the endogenous gene c-Myc, and use the nutrients and space in the culture dish to proliferate normally, which can achieve the purpose of directly improving the efficiency of reprogramming. This result was consistent with the conclusion that VPA can replace the exogenous gene c-Myc and promote the induction efficiency in the process of human ipsc induction (26), so the model system of this experiment was also suitable for human cell reprogramming, but whether there will be side effects requires further research; 2) VPA can significantly increase the expression of VEGFC and other genes, and promote the transformation of fibroblasts to endothelial cells (perhaps due to species specificity). We found for the first time a transition process that was different from the MET process of other species, to speed up the early Bactrian iPSc induction.

\section{Acknowledgments}

Yong Zhang and Zong-Shuai Li designed the study. Zong-Shuai Li conducted the experiments. Xing-Xu Zhao and Jun-Jie $\mathrm{Hu}$ revised the manuscript. Wen-Bo Ge and Yi-Na $\mathrm{Li}$ assisted with the analysis of qRT-PCR data.

This work was supported by the National Natural Science Foundation of China (grants 31960725 and 31560638), China. 


\section{Potential Conflict of Interest}

The authors have no conflicting financial interest.

\section{References}

1. Takahashi K, Yamanaka S. Induction of pluripotent stem cells from mouse embryonic and adult fibroblast cultures by defined factors. Cell 2006;126:663-676

2. Yu J, Vodyanik MA, Smuga-Otto K, Antosiewicz-Bourget J, Frane JL, Tian S, Nie J, Jonsdottir GA, Ruotti V, Stewart $\mathrm{R}$, Slukvin II, Thomson JA. Induced pluripotent stem cell lines derived from human somatic cells. Science 2007;318: 1917-1920

3. Ezashi T, Telugu BP, Alexenko AP, Sachdev S, Sinha S, Roberts RM. Derivation of induced pluripotent stem cells from pig somatic cells. Proc Natl Acad Sci U S A 2009;106: 10993-10998

4. Han X, Han J, Ding F, Cao S, Lim SS, Dai Y, Zhang R, Zhang Y, Lim B, Li N. Generation of induced pluripotent stem cells from bovine embryonic fibroblast cells. Cell Res 2011;21:1509-1512

5. Liao J, Cui C, Chen S, Ren J, Chen J, Gao Y, Li H, Jia $\mathrm{N}$, Cheng L, Xiao H, Xiao L. Generation of induced pluripotent stem cell lines from adult rat cells. Cell Stem Cell 2009;4:11-15

6. Nagy K, Sung HK, Zhang P, Laflamme S, Vincent P, Agha-Mohammadi S, Woltjen K, Monetti C, Michael IP, Smith LC, Nagy A. Induced pluripotent stem cell lines derived from equine fibroblasts. Stem Cell Rev Rep 2011;7: 693-702

7. Liu J, Balehosur D, Murray B, Kelly JM, Sumer H, Verma PJ. Generation and characterization of reprogrammed sheep induced pluripotent stem cells. Theriogenology 2012; 77:338-346.e1

8. Liu H, Zhu F, Yong J, Zhang P, Hou P, Li H, Jiang W, Cai J, Liu M, Cui K, Qu X, Xiang T, Lu D, Chi X, Gao G, Ji W, Ding M, Deng H. Generation of induced pluripotent stem cells from adult rhesus monkey fibroblasts. Cell Stem Cell 2008;3:587-590

9. Buehr M, Meek S, Blair K, Yang J, Ure J, Silva J, McLay R, Hall J, Ying QL, Smith A. Capture of authentic embryonic stem cells from rat blastocysts. Cell 2008;135:12871298

10. Li P, Tong C, Mehrian-Shai R, Jia L, Wu N, Yan Y, Maxson RE, Schulze EN, Song H, Hsieh CL, Pera MF, Ying QL. Germline competent embryonic stem cells derived from rat blastocysts. Cell 2008;135:1299-1310

11. Tulgat R, Schaller GB. Status and distribution of wild Bactrian camels Camelus bactrianus ferus. Biol Conserv 1992;62:11-19

12. Peters J, Driesch Avd. The two-humped camel (Camelus bactrianus): new light on its distribution, management and medical treatment in the past. J Zool 1997;242:651-679

13. Gurvich N, Tsygankova OM, Meinkoth JL, Klein PS. Histone deacetylase is a target of valproic acid-mediated cellular differentiation. Cancer Res 2004;64:1079-1086

14. Phiel CJ, Zhang F, Huang EY, Guenther MG, Lazar MA, Klein PS. Histone deacetylase is a direct target of valproic acid, a potent anticonvulsant, mood stabilizer, and teratogen. J Biol Chem 2001;276:36734-36741

15. Huangfu D, Maehr R, Guo W, Eijkelenboom A, Snitow M, Chen AE, Melton DA. Induction of pluripotent stem cells by defined factors is greatly improved by small-molecule compounds. Nat Biotechnol 2008;26:795-797

16. Giorgetti A, Montserrat N, Aasen T, Gonzalez F, RodríguezPizà I, Vassena R, Raya A, Boué S, Barrero MJ, Corbella BA, Torrabadella $M$, Veiga A, Izpisua Belmonte JC. Generation of induced pluripotent stem cells from human cord blood using OCT4 and SOX2. Cell Stem Cell 2009;5: 353-357

17. Chen X, Zhai Y, Yu D, Cui J, Hu JF, Li W. Valproic acid enhances iPSC induction from human bone marrow-derived cells through the suppression of reprogramming-induced senescence. J Cell Physiol 2016;231:1719-1727

18. Frank DA. Culture of animal cells: a manual of basic technique. Yale J Biol Med 1984;57:247-248

19. Chen M, Zhang H, Wu J, Xu L, Xu D, Sun J, He Y, Zhou X, Wang Z, Wu L, Xu S, Wang J, Jiang S, Zhou X, Hoffman AR, Hu X, Hu J, Li T. Promotion of the induction of cell pluripotency through metabolic remodeling by thyroid hormone triiodothyronine-activated PI3K/AKT signal pathway. Biomaterials 2012;33:5514-5523

20. Zhang H, Jiao W, Sun L, Fan J, Chen $M$, Wang $H$, Xu X, Shen A, Li T, Niu B, Ge S, Li W, Cui J, Wang G, Sun J, Fan X, Hu X, Mrsny RJ, Hoffman AR, Hu JF. Intrachromosomal looping is required for activation of endogenous pluripotency genes during reprogramming. Cell Stem Cell 2013;13:30-35

21. Chen S, Zhou Y, Chen Y, Gu J. fastp: an ultra-fast all-in-one FASTQ preprocessor. Bioinformatics 2018;34: i884-i890

22. Kim D, Langmead B, Salzberg SL. HISAT: a fast spliced aligner with low memory requirements. Nat Methods 2015;12:357-360

23. Love MI, Huber W, Anders S. Moderated estimation of fold change and dispersion for RNA-seq data with DESeq2. Genome Biol 2014;15:550

24. Sun J, Li W, Sun Y, Yu D, Wen X, Wang H, Cui J, Wang G, Hoffman AR, Hu JF. A novel antisense long noncoding RNA within the IGF1R gene locus is imprinted in hematopoietic malignancies. Nucleic Acids Res 2014;42:95889601

25. Wiame I, Remy S, Swennen R, Sági L. Irreversible heat inactivation of DNase I without RNA degradation. Biotechniques 2000;29:252-254, 256.

26. Huangfu D, Osafune K, Maehr R, Guo W, Eijkelenboom A, Chen S, Muhlestein W, Melton DA. Induction of pluripotent stem cells from primary human fibroblasts with only Oct4 and Sox2. Nat Biotechnol 2008;26:1269-1275

27. Moschidou D, Mukherjee S, Blundell MP, Drews K, Jones GN, Abdulrazzak H, Nowakowska B, Phoolchund A, Lay 
K, Ramasamy TS, Cananzi M, Nettersheim D, Sullivan M, Frost J, Moore G, Vermeesch JR, Fisk NM, Thrasher AJ, Atala A, Adjaye J, Schorle H, De Coppi P, Guillot PV. Valproic acid confers functional pluripotency to human amniotic fluid stem cells in a transgene-free approach. Mol Ther 2012;20:1953-1967

28. Ben-Nun IF, Montague SC, Houck ML, Tran HT, Garitaonandia I, Leonardo TR, Wang YC, Charter SJ, Laurent LC, Ryder OA, Loring JF. Induced pluripotent stem cells from highly endangered species. Nat Methods 2011;8:829-831

29. Lluis F, Pedone E, Pepe S, Cosma MP. Periodic activation of Wnt/beta-catenin signaling enhances somatic cell reprogramming mediated by cell fusion. Cell Stem Cell 2008;3:493-507

30. Yang Y, Liu B, Xu J, Wang J, Wu J, Shi C, Xu Y, Dong J, Wang C, Lai W, Zhu J, Xiong L, Zhu D, Li X, Yang W, Yamauchi T, Sugawara A, Li Z, Sun F, Li X, Li C, He A, Du Y, Wang T, Zhao C, Li H, Chi X, Zhang H, Liu Y, Li C, Duo S, Yin M, Shen H, Belmonte JCI, Deng H. Derivation of pluripotent stem cells with in vivo embryonic and extraembryonic potency. Cell 2017;169:243-257. e25

31. Hou P, Li Y, Zhang X, Liu C, Guan J, Li H, Zhao T, Ye J, Yang W, Liu K, Ge J, Xu J, Zhang Q, Zhao Y, Deng H. Pluripotent stem cells induced from mouse somatic cells by small-molecule compounds. Science 2013;341:651-654

32. Zhao Y, Zhao T, Guan J, Zhang X, Fu Y, Ye J, Zhu J, Meng G, Ge J, Yang S, Cheng L, Du Y, Zhao C, Wang
T, Su L, Yang W, Deng H. A XEN-like state bridges somatic cells to pluripotency during chemical reprogramming. Cell 2015;163:1678-1691

33. Cao S, Yu S, Li D, Ye J, Yang X, Li C, Wang X, Mai Y, Qin Y, Wu J, He J, Zhou C, Liu H, Zhao B, Shu X, Wu C, Chen R, Chan W, Pan G, Chen J, Liu J, Pei D. Chromatin accessibility dynamics during chemical induction of pluripotency. Cell Stem Cell 2018;22:529-542.e5 34. Armstrong L, Hughes O, Yung S, Hyslop L, Stewart R, Wappler I, Peters H, Walter T, Stojkovic P, Evans J, Stojkovic M, Lako M. The role of PI3K/AKT, MAPK/ERK and NFkappabeta signalling in the maintenance of human embryonic stem cell pluripotency and viability highlighted by transcriptional profiling and functional analysis. Hum Mol Genet 2006;15:1894-1913

35. Hong H, Takahashi K, Ichisaka T, Aoi T, Kanagawa O, Nakagawa M, Okita K, Yamanaka S. Suppression of induced pluripotent stem cell generation by the p53-p21 pathway. Nature 2009;460:1132-1135

36. Rasmussen MA, Holst B, Tümer Z, Johnsen MG, Zhou S, Stummann TC, Hyttel P, Clausen C. Transient p53 suppression increases reprogramming of human fibroblasts without affecting apoptosis and DNA damage. Stem Cell Reports 2014;3:404-413

37. Soufi A, Donahue G, Zaret KS. Facilitators and impediments of the pluripotency reprogramming factors' initial engagement with the genome. Cell 2012;151:994-1004

38. Apostolou E, Hochedlinger K. Chromatin dynamics during cellular reprogramming. Nature 2013;502:462-471 